\title{
Is the Loudness Dependence of the Auditory Evoked Potential a Sensitive and Selective In Vivo Marker of Central Serotonergic Function?
}

\author{
Pradeep J Nathan*,', Barry O'Neill' and Rodney J Croft' \\ 'Behavioural Neuroscience Laboratory, Department of Physiology, Monash Centre for Brain and Behaviour, Monash University, Vic., Australia
}

Neuropsychopharmacology (2005) 30, I584-1585. doi:I 0.1038/sj.npp. I 300775

Sir

Lang et al (2005) reported a negative association between serum brain-derived neurotrophic factor (BDNF) levels and central serotonergic neurotransmission as measured by the loudness dependence (LD) of the auditory-evoked potential (AEP). The authors suggest that low serum BDNF concentrations reflect low central serotonergic neurotransmission as indicated by the strong LD of the AEP. While these findings are interesting and may suggest a relationship between central serotonin neurotransmission and serum BDNF levels, they need to be viewed with caution for a number of reasons.

First, the relationship between LD of the AEP (LDAEP) and serotonin function in humans is tenuous, with the most convincing evidence for a direct relationship coming from animal studies exploring the $5-\mathrm{HT}_{1 \mathrm{~A}}$ receptor system (Juckel et al, 1997), with no such studies conducted in humans. Second, the specificity of the LDAEP as a marker of serotonin neurotransmission is questionable. For example, dopamine metabolites in CSF and urine have been found to correlate with the intensity dependence of visual and auditory N1/P2 components (Von Knorring and Perris, 1981), and Juckel et al (1997) also found that the $D_{1} / D_{2}$ agonist apomorphine decreased the intensity dependence in animals, and more recently, a study in patients with obsessive-compulsive disorder found a correlation between the LDAEP and striatal dopamine transporter (DAT)

\footnotetext{
Submitted as a Letter to the Editor discussing a recent article by Lang and colleagues, titled 'Association of BDNF serum concentrations with central serotonergic activity: Evidence from auditory signal processing'. Neuropsychopharmacology (2005): Advanced online publication. 19 January 2005; doi: I 0.1 038/sj.npp. I 300666

*Correspondence: Dr PJ Nathan, Department of Physiology, Monash Centre for Brain and Behaviour, PO Box I3F, Monash University, Vic. 3800, Australia, Tel: + II 6139905 2553, Fax: + II 6139905 2547, E-mail: Pradeep.Nathan@med.monash.edu.au

Received 17 March 2005; revised 23 March 2005; accepted 19 April 2005

Online publication: 19 April 2005 at http://www.acnp.org/citations/ Npp041905050188/default.pdf
}

binding (Pogarell et al, 2004). Consequently, only a relative specificity can be expected with regard to the LDAEP and its relationship to functional aspects of the serotonergic system. It is apparent that further studies are required to clarify the direct role of serotonin and other neuromodulators on LDAEP before this measure could be considered an in vivo marker of central serotonergic system. Accordingly, we have recently demonstrated, for the first time, a direct relationship between enhanced serotonin neurotransmission and the LD of the AEP in humans (Simmons et al, 2003; Nathan et al, 2005). In these studies, we demonstrated that both acute and chronic serotonin enhancement (using the serotonin reuptake inhibitors, citalopram and sertraline) resulted in a reduction of the slope of the LD of the AEP.

Finally, while there are interactions between BDNF and the serotonergic system, similar interactions have also been noted between BDNF and the dopaminergic system. For example, in vitro survival, differentiation and function of dopamine neurons have been shown to be promoted by BDNF (Beck et al, 1993; Spina et al, 1992; Hyman et al, 1994). Furthermore, dopamine and $D_{1}$ receptor agonists have been shown to increase BDNF mRNA and protein, indicating a potential role for dopamine in BDNF expression (Kuppers and Beyer, 2001).

These findings, together with the demonstration of a relationship between the LDAEP and dopamine neurotransmission, suggest that the results of the study by Lang and colleagues may in part be influenced by the dopaminergic system.

In summary, the relationship between the LDAEP and serotonergic neurotransmission, while promising, requires more direct validation. Given the lack of selectivity of both the LDAEP and BDNF for the serotonergic system, the findings of the Lang et al (2005) study need to be interpreted with caution.

\section{REFERENCES}

Beck K, Knusel B, Hefti F (1993). The nature of the trophic action of brain-derived neurotrophic factor, des(1-3)-insulin-like growth factor-1, and basic fibroblast growth factor on mesence- 
phalic dopaminergic neurons developing in culture. Neuroscience 52: 855-866.

Hyman C, Juhasz M, Jackson C, Wright P, Ip NY, Lindsay RM (1994). Overlapping and distinct actions of the neurotrophins BDNF, NT-3 and NT-4/5 on cultured dopaminergic and GABAergic neurons of the ventral mesencephalon. J Neurosci 14: 335-347.

Juckel G, Molnar M, Hegerl U, Csepe V, Karmos G (1997). Auditory-evoked potentials as indicator of brain serotonergic activity-first evidence in behaving cats. Biol Psychiatry 41: 1181-1195.

Kuppers E, Beyer C (2001). Dopamine regulates brain-derived neurotrophic factor (BDNF) expression in cultured embryonic mouse striatal cells. Neuroreport 12: 175-1179.

Lang UE, Hellweg R, Gallinat J (2005). Association of BDNF serum concentrations with central serotonergic activity: evidence from auditory signal processing. Neuropsychopharmacology 30: 1148-1153.

Nathan PJ, Segrave R, Phan KL, O’Neill B, Croft RJ (2005). Direct evidence that acutely enhancing serotonin with a selective serotonin uptake inhibitor modulates the Loudness Dependence of Auditory Evoked Potential (LDAEP). Hum Psychopharmacol (submitted).

Pogarell O, Tatsch K, Juckel G, Hamann C, Mulert C, Popperl G et al (2004). Serotonin and dopamine transporter availabilities correlate with the loudness dependence of auditory evoked potentials in patients with obsessive-compulsive disorder. Neuropsychopharmacology 29: 1910-1917.

Simmons JG, Allen NB, Berger G, Nathan PJ (2003). The influence of chronic sertraline administration on the loudness dependence of the auditory evoked potential in healthy subjects. Psychophysiology 40: S80.

Spina MB, Squinto SP, Miller J, Lindsay RM, Hyman C (1992). Brain-derived neurotrophic factor protects dopamine neurons against 6-hydroxydopamine and $\mathrm{N}$-methyl-4-phenylpyridinium ion toxicity: involvement of the glutathione system. J Neurochem 59: 99-106.

Von Knorring L, Perris C (1981). Biochemistry of the augmenting/ reducing response in visual evoked potentials. Neuropsychobiology 7: 1-8. 